\title{
Operationalization of self-regulation in the early years: comparing policy with theoretical underpinnings
}

\author{
Heather Braund ${ }^{*}(10$ and Kristy Timmons
}

\section{*Correspondence:}

heather.braund@queensu.ca

Faculty of Education, Queen's

University, Duncan McArthur

Hall, 511 Union Street,

Kingston, ON K7M 5R7,

Canada

\begin{abstract}
Research has consistently demonstrated that self-regulation is essential for the development and preservation of health and well-being in the early years and across the lifespan. Based on the emerging literature on the important role of self-regulation in promoting healthy child development, policymakers have made efforts to include selfregulation skills in practice and policy documents worldwide. Despite efforts to include self-regulation skills in early years curriculum documents, there is limited understanding by teachers, scholars, and policymakers of what self-regulation is and how best to support it in the day-to-day classroom. This limited understanding is perpetuated by a lack of a unified definition of self-regulation. Thus, it becomes important to examine these efforts in a critical way. In Ontario, where the research was completed, a revised play-based full-day kindergarten program was introduced in 2016. In this research we use a qualitative document analysis approach to compare the conceptualization of self-regulation in Ontario's revised play-based kindergarten program with theory-driven models of self-regulation from empirical research. Analysis was iterative, and themes emerged based upon a coding scheme developed by the research team. Results suggest that co-regulation has a powerful influence on student learning. In addition, the policy document de-emphasizes behavioral regulation and expands cognitive regulation to include more than inhibitory control. Lastly, the kindergarten program discusses metacognition in relation to the use of language to articulate one's thinking with little attention to goal-directed behaviors. In this paper, explicit recommendations for policymakers and practitioners are provided to ensure that emerging conceptualizations of self-regulation are promoted in early years curricula. Further, empirical evidence is needed to support why it is necessary to understand emerging conceptualizations of self-regulation and outline implications for current early years curricula.
\end{abstract}

Keywords: Document analysis, Early years, Kindergarten curriculum, Self-regulation

\section{Background}

Kindergarten programs around the world are required to balance having to integrate developmentally appropriate practices such as play-based learning (Lynch, 2014) and standards-based curriculum (Gullo \& Hughes, 2011). However, this balance has resulted in some kindergarten curricula integrating academic learning outcomes into play

(c) The Author(s), 2021. Open Access This article is licensed under a Creative Commons Attribution 4.0 International License, which permits use, sharing, adaptation, distribution and reproduction in any medium or format, as long as you give appropriate credit to the original author(s) and the source, provide a link to the Creative Commons licence, and indicate if changes were made. The images or other third party material in this article are included in the article's Creative Commons licence, unless indicated otherwise in a credit line to the material. If material is not included in the article's Creative Commons licence and your intended use is not permitted by statutory regulation or exceeds the permitted use, you will need to obtain permission directly from the copyright holder. To view a copy of this licence, visit http:// creativecommons.org/licenses/by/4.0/. 
sessions. For example, in Singapore, there has been a focus on 'purposeful play' which posits that play sessions are intentionally planned and facilitated in order to achieve the predetermined learning outcomes (Nicolopoulou, 2010). A study by Bautista and colleagues (2019) examined Learning Centre Time (LCT) in 108 Kindergarten classrooms in Singapore. Following the collection of video data, they found that certain subjects were prioritized more (literacy and arts) than other subjects (numeracy and science). Teachers were present $68 \%$ of the time at the learning centers and were found to be interacting with children or observing them. Some of the students were also provided with the opportunity to choose materials and resources in $80 \%$ of the classrooms. However, it is important to note that the materials and resources had already been pre-selected by teachers. The classroom observations highlighted that teachers acted as facilitators to varying degrees. Further, the quality of instructional support was low across learning centers. The authors concluded that the current curricular vision was not adequately integrated across the 108 Kindergarten classrooms citing a theory/practice gap.

Numerous learning benefits resulting from changes to Kindergarten programming include increased instructional time, improved academic outcomes, and a focus on developing self-regulation (Youmans et al., 2018). Self-regulation develops across the lifespan, but there is evidence suggesting that the first five years of life are particularly important for self-regulation development (Timmons et al., 2016, 2019; McCain et al., 2011). Self-regulation skills in kindergarten are related to improved learning outcomes and achievement (Blair \& Raver, 2015; Edossa et al., 2017; McClelland \& Cameron, 2012). Furthermore, measures of self-regulation in the early years have shown to predict future academic success, physical and mental health, income, occupational attainment, and risk taking behaviors (Blair \& Raver, 2015; Duckworth, 2011; McClelland \& Cameron, 2012; Moffitt et al., 2011; Pandey et al., 2018; Timmons et al., 2016, 2019; Zimmerman, 2002).

Self-regulation involves the ability to monitor one's behaviors, emotions, cognitive processes, and social interactions within academic contexts (Zimmerman \& Schunk, 2001) and within specific academic domains or skills such as mathematics (e.g., Blair \& Razza, 2007; Cleary \& Chen, 2009) and reading (Becker et al., 2014; Lonigan et al., 2017). The various aspects of self-regulation have different developmental trajectories with emotional regulation typically developing prior to behavioral regulation skills (Howse et al., 2003). Researchers emphasize that by the time children are three years of age, behavioral regulation skills develop at a faster rate than they have previously (Best \& Miller, 2010; Rothbart et al., 2006).

Research over the past decade has broadened to include an examination of how individuals can support others in regulating their behaviors often referred to as co-regulation and socially shared regulation (e.g., Hadwin et al., 2010, 2011). Co-regulation occurs when one learner is supported by another or multiple learners to perform a specific task and develop self-regulatory skills (McCaslin \& Hickey, 2001). Socially shared regulation is the process of multiple learners regulating an activity at the onset of the task which includes co-construction of the goals and strategies used (Jackson et al., 2000). More recently, researchers are beginning to examine the role of motivational beliefs in self-regulation (e.g., Scholer et al., 2018) and conceptually relating self-regulation to classroom assessment (e.g., Chen \& Bonner, 2019). Generally, research has focused on 
connecting one specific aspect of classroom assessment to self-regulation, formative assessment which is the process of collecting data and sharing feedback to further direct student learning. The process of formative assessment can be facilitated by the teacher or by the students. Encouraging students to self-assess, reflect, or peer-assess puts them at the center of the assessment process (Clark, 2012; Panadero et al., 2018). By engaging students in the process of formative assessment they can better understand the learning conditions including the expectations while also providing them with a sense of agency (Clark, 2012; Smith et al., 2016). Formative assessment provides students with the opportunity to select different learning strategies, implement the strategies, and then reflect on the extent to which their strategies allowed them to attain their learning goals (Clark, 2012). Metacognition and self-regulation are related concepts; students need to be able to think about their learning and understand their cognitive processes (metacognition) in order to regulate their behaviors (Zimmerman, 2002). The conceptualization of self-regulation is broadening as it now encompasses the involvement of others as a strategy to help develop regulatory behaviors, thus, there is increased interest in how student involvement in various assessment processes can also encourage co-regulation (Panadero et al., 2018).

\section{Conceptualizations of self-regulation}

Traditionally, self-regulation was defined as the ability to control behaviors and emotions (Bandura, 1982, 1986). This conceptualization has evolved to include individual and social aspects including the ability to regulate behavior, cognition, and emotions, when working to accomplish a goal (Bauer \& Baumeister, 2011; Diamond \& Lee, 2011; Zimmerman, 2000). A facet of self-regulation, termed self-regulated learning, focuses on how a learner plans for their learning, uses various strategies, and engages in ongoing efforts to meet their desired goals. Through a social psychological lens, self-regulated learning can be understood through a cyclical process consisting of the forethought phase, the performance phase, and the self-reflection phase (Zimmerman, 2002). The forethought phase includes processes and an individual's beliefs before they start engaging in the learning process. This might include self-efficacy beliefs or setting goals. The second phase, performance phase is centered around processes that occur during the period of learning such as using strategies and maintaining focus. Lastly, the third phase, termed the self-reflection phase includes processes after the period of learning such as evaluating the extent to which the goal was met, and the amount of satisfaction experienced by the learner.

According to Stuart Shanker, self-regulation is focused on how an individual manages stress and recovers through five domains: biological, emotional, cognitive, social, and prosocial (Shanker, 2017a, 2017b). Further, this model acknowledges the difference between self-regulation and self-control, emphasizing that self-control is not part of self-regulation as it is a short-term strategy. In this model, a child is unable to regulate their behaviors because they are not in a calm and focused state. Therefore, the role of educators and other adults is to help keep children calm and decrease their stress levels so that they are able to regulate their behaviors (Shanker, 2017a, 2017b). The process of self-regulation can be achieved through five steps. First educators and guardians need to be able to identify the signs of stress followed 
by identifying what is causing the stress. The educators and caregivers then need to work to decrease the stress and reflect to develop further awareness about the stress witnessed. Lastly, educators and caregivers can help teach the child how they can manage and alleviate the stressors themselves working towards restoring their body to a state of calm.

Despite the models of self-regulation discussed above, self-regulation as a construct remains fragmented and lacks a unified definition across contexts. This lack of a unified definition adds an additional barrier as practitioners work to develop students' self-regulation skills (Boekaerts \& Corno, 2005; Burman et al., 2015). Despite the fragmentation of the field, it is well understood that self-regulation is malleable and can be developed from a young age. Thus, early childhood educators and teachers are in a unique position to support the development of self-regulation in students in the early years. More specifically, this can be accomplished by providing students with explicit opportunities to practice regulating their behaviors, emotions, social interactions, and cognitive processes with direct feedback (Meusen-Beekman et al., 2015).

As mentioned earlier, one strategy used to develop students' self-regulatory skills is co-regulation, a type of social regulation and scaffolding strategy (Bailey \& Heritage, 2018). Co-regulation is the process of a 'more capable' individual regulating another individual (McCasslin, 2009). Teachers are in an excellent position to act as the 'more capable' other to regulate their students until they are able to self-regulate. A study conducted by Kurki and colleagues (2016) examined how early childhood teachers engaged in co-regulation in childcare settings. They collected video data of challenging social and emotional situations and used these videos to guide interviews with teachers $2-4$ weeks following the observations. The findings reveal that teachers use a variety of strategies to help students regulate themselves including providing instructions for their behavior, providing a solution verbally, and encouraging discussion of emotions. During instances that were more challenging, teachers would use multiple strategies. The results demonstrated that teachers have some awareness of their use of co-regulation strategies, but could benefit from increased awareness.

Traditionally, researchers did not believe that young children were capable of self-regulating; however, the work of Schunk and Zimmerman (1994) revealed that these skills can be developed during the preschool years. By 2007, Whitebread and colleagues moved the field forward by providing classroom observational data suggested that students between three and five years of age were capable of demonstrating early variations of self-regulatory behaviors such as correcting the behaviors of other students by pointing and gesturing or by verbally providing them with corrective instructions. Methodological limitations have been offered as one barrier as to why early research on self-regulation did not showcase the capabilities of young children, including developmentally inappropriate tools for measuring self-regulation in young children (Whitebread et al., 2009). With the development of new tools for measuring self-regulation behaviors in young children (e.g., Perels et al., 2009; Ponitz et al., 2009; Whitebread et al., 2009), we can work towards better understanding how young children are able to regulate their behaviors in the early years. 


\section{Early childhood and play}

Play provides an important and developmentally appropriate vehicle for children to learn (Bergen, 2009; Pyle \& DeLuca, 2017). Scholars have identified the essentials tenants of 'play' including that it must be enjoyable, children must be able to have choice, children are engaged, and if they can modify the activity (Neumann, 1971). Additionally, play provides a mechanism for communication in children, play offers the opportunity for children to be creative and explore various materials, and their thoughts can be articulated through play as their language skills continue to develop. Other benefits of play include that it is an avenue for children to take risks, play can also empower children as they convey their ideas, and lastly play provides an ideal learning environment where children can function naturally (Bergen, 2009).

One challenge is that there is controversy over what is meant by play-based learning (Hawes et al., 2012; Pyle \& Danniels, 2017). At one end of the spectrum are those that believe that play-based learning means providing children with unstructured play that is free from adult influence or interference (e.g., "free play"), while at the other end of the spectrum are those who see play-based learning as an opportunity to structure play for children with pre-established rules and expectations that should be followed (Hawes et al., 2012). Similarly, Pyle and Danniels (2017) found two different profiles in regard to teacher understanding of play-based learning (Pyle \& Danniels, 2017). The first profile saw play and learning as separate constructs, these educators reported challenges in meeting academic demands using a play-based approach (children in these classrooms were primarily observed engaging in free play). The second profile included educators who believed that play supported academic learning and that teachers have an important role in supporting learning through play (children in these classrooms engaged in a variety of play opportunities that were situated along a continuum from child-directed to more teacher-directed play).

\section{Self-regulation and play}

Self-regulation as a process continues to expand in empirical literature; thus, there is a need to understand the ways in which this expansion is reflected in mandated early learning curriculum and policy documents. In Ontario, where the research was completed, a revised play-based full-day early learning kindergarten program was introduced in 2016 in a time and context in which a growing body of evidence pointed to the importance of play and self-regulation in promoting healthy child development (e.g., Bodrova \& Leong, 2008; Durlak et al., 2011; Moffitt et al., 2010). Furthermore, research in the past decade also suggests that self-regulation and play are linked developmentally (Diamond \& Lee, 2011; Timmons, 2019). When children are engaged in play, they develop and practice skills that are essential to self-regulated learning. For example, play provides opportunities for children to engage in flexible thinking, sustained attention, and goaldirected behavior. These are the types of behaviors that theorists argue are at the core of self-regulation (Baumeister \& Vohs, 2011; Vohs \& Baumeister, 2017). Taken together, the above research findings provide robust justification for investment in play-based programming. Despite growing knowledge that self-regulation can be fostered through play, little is known about what differentiates effective forms of play. For example, in 2008, Blair and Diamond noted that although the Tools of the Mind Curriculum (an early 
childhood curriculum designed to foster children's executive function skills) fosters selfregulation skills, it was unclear what specific aspects of teacher-child and child-child interactions and play actually contribute to the development of self-regulation.

Given the controversy of what is meant by play-based learning it is not surprising that there is a lack of clarity in regards to what types of play foster self-regulated learning. This is further problematized by the lack of unified definition of self-regulation (Burman et al., 2015). Therefore, more research is needed in understanding the ways in which play-based learning and self-regulation are defined and promoted in practice and policy documents while also examining how these conceptualizations map onto definitions found in empirical literature. This research is necessary to ensure that policies involving play-based learning and self-regulation are aligned with theoretical conceptions in order to best equip teachers for success in the classroom using evidence-based practices. Thus, the purpose of this research is to understand and compare practice-oriented conceptualizations of self-regulation in a play-based policy document with theory-driven definitions from empirical literature. This research is important in understanding the extent to which practice-oriented conceptualizations are guided by the theoretical underpinnings of self-regulation. In this research, a qualitative document analysis was conducted to compare the conceptualization of self-regulation in Ontario's play-based Kindergarten program (Ontario Ministry of Education, 2016) with theory-driven models of self-regulation from empirical research. The results of this research indicate a need for policymakers to consider emerging conceptualizations of self-regulation when promoting the development of self-regulatory skills in kindergarten.

\section{Setting the context}

Ontario's full-day kindergarten program was phased in over five years, beginning in 2010, with the goal to provide universally accessible Junior and Senior full-day (5 days a week) kindergarten across Ontario. The Kindergarten program is not mandatory in Ontario although the majority of parents/guardians opt to register their children in Kindergarten. There is also no cost for attending Kindergarten in Ontario (Ontario Ministry of Education, 2021a). Enrollment during the 2019-2020 year included 130,230 students in Junior Kindergarten and 136,544 in Senior Kindergarten (Ontario Ministry of Education, 2021b). The purpose of the full-day kindergarten program is to establish a strong foundation for learning that is child-centered, developmentally appropriate, and integrated for four- and-five-year-old children (Ontario Ministry of Education, 2016). A child-centered approach is achieved in the full-day kindergarten program through a play-based environment that promotes the physical, social, emotional, and cognitive development of all children. Six fundamental principles guide the full-day kindergarten program and are reflective of the values, beliefs and best practices of current research in early learning (Ontario Ministry of Education, 2016). Principle 5 specifically acknowledges the link between play and learning for young children, "play is a means to early learning that capitalizes on children's natural curiosity and exuberance" (p. 4). Both child-initiated and teacher structured play-based learning are integral to successful implementation of the program (Ontario Ministry of Education, 2016). Play has an important role in early learning and can be used to further learning in all areas of the full-day kindergarten program (Ontario Ministry of Education, 2016). 
The full-day kindergarten program provides a "single program with a single pedagogical and curriculum approach planned and delivered by qualified educators using common space and resources" (Pascal, 2009, p. 20). Ontario's full-day kindergarten program is not simply a doubling of time; unique foundational elements include the professional knowledge base of a Registered Early Childhood Educator and a Kindergarten teacher who work collaboratively as partners in implementing a play-based curriculum. The draft full-day kindergarten program was published in 2010. In 2016, an updated kindergarten curriculum was introduced. The 2016 Kindergarten Program replaces the 2010 curriculum. Therefore, beginning in September 2016, all Kindergarten programs began to utilize the updated curriculum (Ontario Ministry of Education, 2016). The updated curriculum incorporates the transformational changes in pedagogical approaches described in the 2010 curriculum, including the movement from a traditional pedagogy to a child-centered play-based program, and adds insights from educators working in the field along with additional research on early learning (Ontario Ministry of Education, 2016). These revisions included the addition of four learning frames that are included to structure thinking, learning, and assessment in Kindergarten (Ontario Ministry of Education, 2016). The frames include: (1) belonging and contributing, (2) self-regulation and well-being, (3) demonstrating literacy and mathematics behaviors, and (4) problem solving and innovating. The four frames include aspects of learning that are critical to young children's learning. It was not surprising that given the increase in empirical literature on the importance of self-regulation that the revised 2016 kindergarten program included a focus on self-regulation as a key area of learning within the play-based curriculum. The unique play-based kindergarten curriculum in Ontario with a focus on self-regulation provided an opportunity to compare the conceptualization of self-regulation within this curriculum with theory-driven models of self-regulation from empirical research.

\section{Methodology}

This study was conducted during the 2018-2019 year. The Ontario Kindergarten curriculum (Ontario Ministry of Education, 2016) was systematically analyzed using a qualitative document analysis technique (Bowen, 2009) to accomplish the research purpose of understanding and comparing a practice-oriented conceptualization of self-regulation with theory-driven definitions from empirical literature. Prior to completing the document analysis, a closer reading of the full-day kindergarten curriculum was completed to allow the team to make note of interesting and relevant content relating to self-regulation. This process represented an approach to content analysis as outlined by Bowen (2009) allowing the researchers to ensure the focus was on relevant rather than irrelevant passages of text in relation to the purpose. Next, an in-depth line-by-line reading was completed. The research team modified a previously constructed coding framework based upon work with early years curricular documents and relevant literature published earlier (Timmons et al., 2016, 2019). Literature published in the past decade was examined to better understand how the predetermined codes had been articulated and operationalized. During this process, consistently used terms from the literature were noted. Terms that were regularly discussed in the literature but were not originally included in the coding framework were also recorded. Definitions were constructed individually for each code (see Table 1 for examples of the co-constructed definitions). 
Each researcher constructed their own definition independently for each key construct as demonstrated in Table 1. After each researcher had their own definition for all constructs, the two researchers met to discuss. During this discussion, the researchers identified common elements between the two definitions. The common elements were then used to develop a 'mutually constructed definition' found in Table 1. This process was repeated for each construct to ensure that the coders had shared understanding of each of the key constructs.

Following the initial scan, the curriculum was examined line-by-line a second time using the coding framework, each code was counted, and example quotes noted. During this process the coding scheme evolved to capture key operationalizations of self-regulation within the curriculum. The research team continued to meet regularly to share the codes, frequencies, and example quotes. During instances where the lead coder was unsure of how to code a sentence, they would make a note of the sentence and discuss with the research team to ensure appropriate coding. The occurrence of a key term was only coded (counted as occurring) if the sentence in which it occurred was considered relevant to the self-regulation category according to our definition. For example, if the word 'focus' came up in a sentence like "This section focuses on literacy", it was not included. However, if it came up in a sentence like "The child is able to focus on a task", it was included. The consensus-built codebook consisted of 154 codes in total organized into 13 categories. An iterative process involved grouping individual codes into categories and these categories were organized into broader themes. These four themes that emerged represented ongoing patterns interpreted across the whole data set focusing on understanding the main ideas around self-regulation and affiliated constructs. Frequencies for each code and example quotations were recorded. The themes were then compared with literature-based conceptualizations of self-regulation and affiliated constructs. The empirical literature was examined for similarities and discrepancies relating to the four emergent themes. Key words used to examine the literature included different combinations of the following self-regulation, self-regulated learning, early years, metacognition, and executive functioning. Additionally, papers from seminal authors in the field of self-regulation were hand searched to compare with the four emergent themes.

The research team met on a bi-weekly basis to discuss individual definitions and identify common elements to mutually construct a definition for each code. Upon further discussion, the research team recognized that there was a need to delve deeper into the literature regarding: inhibitory control, co-regulation, shared regulation, and learning dispositions. Discussions occurred until consensus was reached for each definition. More specifically, the research team co-constructed definitions to enhance the clarity of the key terms before commencing the coding process. Therefore, the development of the consensus-built codebook was an iterative process and continued to be refined until the research team felt that it was accurately capturing the key elements of self-regulation and its related sub-constructs. Each sentence throughout the curriculum was coded using the consensus-built coding framework. If the sentence was not relevant to self-regulation, then it was not coded. See Figs. 1 and 2 for example screenshots of the coding framework. During instances of uncertainty, the sentences of interest and interpretations were discussed by the 


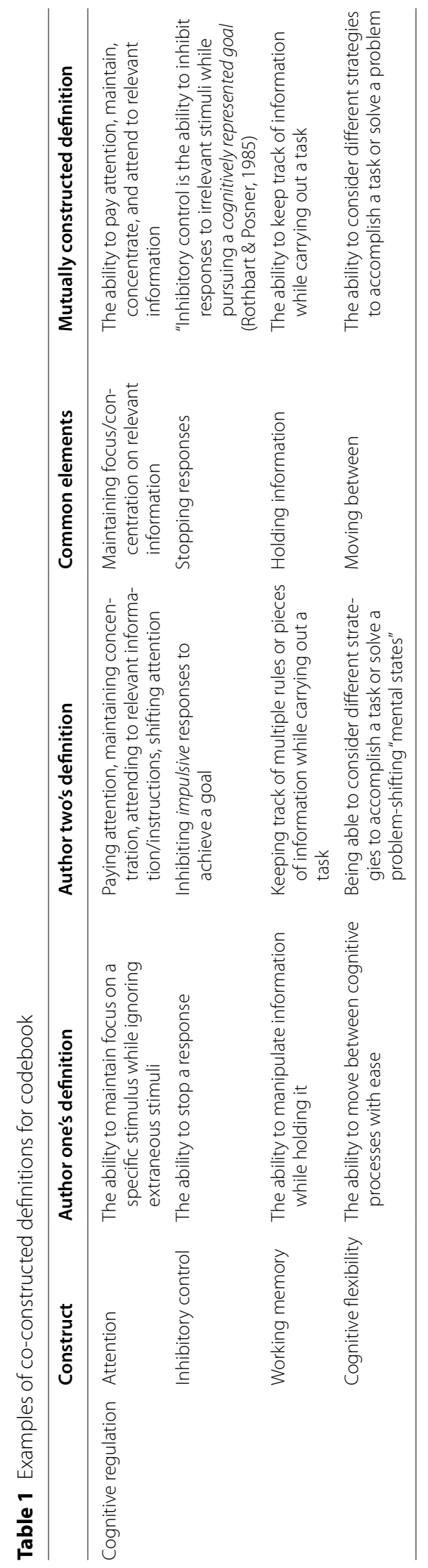




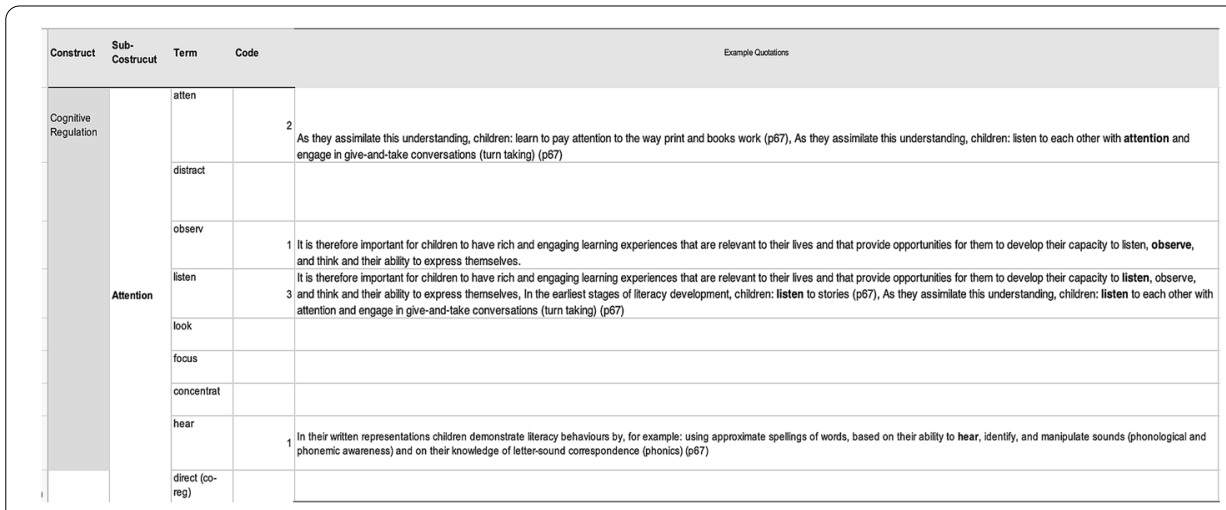

Fig. 1 Example screenshot of Cognitive Regulation for the 'Thinking About Literacy and Mathematics'frame of the kindergarten curriculum

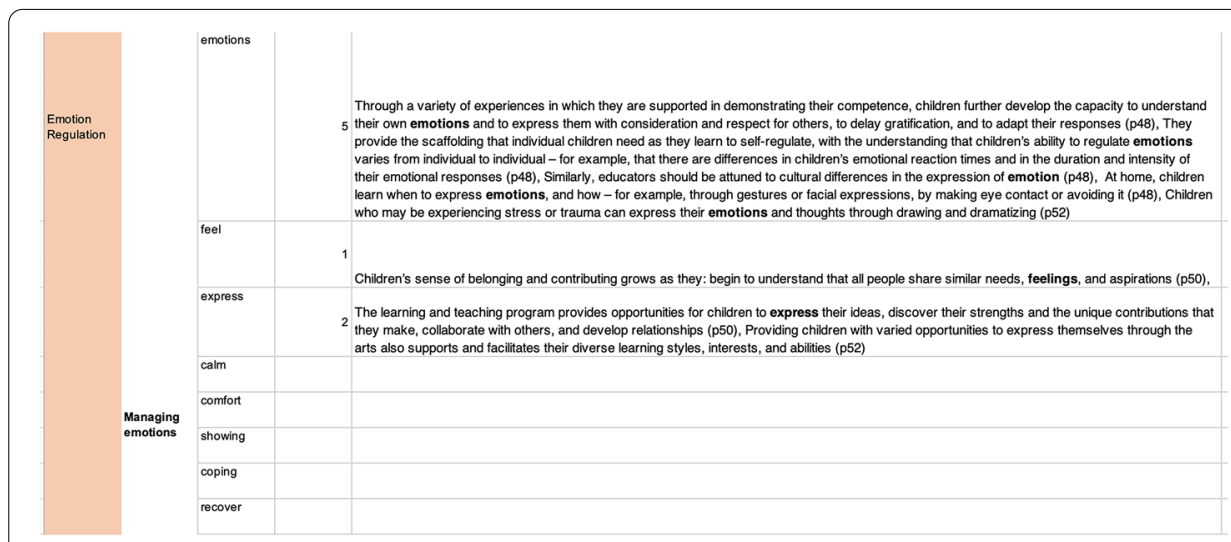

Fig. 2 Screenshot of Emotional Regulation for the 'Thinking About Belonging and Contributing' frame in the kindergarten curriculum

two researchers until consensus was reached. This was followed by an interpretation of the documented codes and emerging themes. Ten percent of the curriculum was scanned and coded independently by a third rater. There was $95 \%$ agreement for the related sub-constructs. We had agreed on a cutoff of $90 \%$ for inter-rater reliability and therefore, 95\% agreement exceeded our established criteria. The final codebook contained six constructs: cognitive regulation, emotion regulation, approaches to learning, behavior regulation, social regulation, and resilience.

\section{Research team}

The research team has extensive teaching and research experience in the field of early childhood education and self-regulation (an average of 8.5 years). Two primary researchers who are specialized in early years and developmental psychology led this document analysis. A third researcher (who specialized in early years and self-regulation) was consulted to code a sample of the document in order to assess inter-rater reliability. 
Table 2 Overview of Theme 1, example codes, and quotations

\begin{tabular}{|c|c|c|}
\hline Theme & Example codes & Example quotations \\
\hline \multirow[t]{2}{*}{ 1. The power of co-regulation } & Interact & $\begin{array}{l}\text { "Through their interactions with } \\
\text { peers and adults in connection- } \\
\text { building relationships in the } \\
\text { classroom, however, children } \\
\text { will begin-or will continue-to } \\
\text { develop self-awareness and a } \\
\text { stronger sense of self (p. 56)." } \\
\text { "With this support, and through } \\
\text { connection-building interactions } \\
\text { with educators, children develop } \\
\text { meaningful relationships that help } \\
\text { foster a positive sense of self and a } \\
\text { sense of belonging and contribut- } \\
\text { ing (p. 47)." }\end{array}$ \\
\hline & Collaborat(e)(ing) & $\begin{array}{l}\text { "Kindergarten children are engaging } \\
\text { in innovative thinking when they } \\
\text { do any of the following: collaborate } \\
\text { with peers to create and modify } \\
\text { things, using their own ideas and } \\
\text { building on the ideas of others (p. } \\
\text { 89)" } \\
\text { "The examples in the previous sec- } \\
\text { tion illustrate how educators, in } \\
\text { their interactions with the children, } \\
\text { constantly engage in a creative } \\
\text { collaboration with them to co- } \\
\text { construct thinking and learning } \\
\text { (p. 24)" }\end{array}$ \\
\hline
\end{tabular}

\section{Data sources}

\section{Results}

Four themes emerged from the review: (1) the power of co-regulation; (2) a de-emphasis of behavior regulation toward a focus on emotional regulation; (3) cognitive regulation encompasses far more than inhibitory control, and (4) the use of language in supporting metacognition. Resilience and affiliated constructs were discussed to a much lesser extent than the other key constructs hence a full theme did not emerge for resilience.

\section{Theme 1: the power of co-regulation}

The need for students to be provided with multiple opportunities throughout the school year for co-regulation to occur was emphasized throughout the play-based curriculum. This process of co-regulation was described between students and educators, but also between students and their fellow peers. The codes mentioned most frequently within co-regulation included: interact, share, social, and collaborate. Engaging techniques and the use of questioning were also suggested within the curriculum as ways to support co-regulation. For example, purposeful co-construction of the learning environment was seen as a strategy to effectively engage students. More specifically, the play-based curriculum states, "educators report that children become much more engaged in their learning when the learning environment is planned and designed in negotiation with the children - that is, when "the children's voice" is heard in planning the environment and organizing and selecting materials for learning (p. 32)" Part of this negotiation can include sharing self-regulatory processes (see Table 2 for an overview of Theme 1 with 
Table 3 Overview of Theme 2, example codes, and quotations

\begin{tabular}{lll}
\hline Theme & Example codes & Example quotations \\
\hline $\begin{array}{ll}\text { 2. De-emphasis of behavior regulation } \\
\text { toward a focus on emotional regulation }\end{array}$ & Adapt & "adapting to distractions (p. 15)." \\
& Sustain & "As part of making children's transition to \\
& Kindergarten easier, educators endeavour to \\
& maintain a sense of calm in the classroom \\
& and provide large blocks of time to engage \\
& children's attention in sustained, complex \\
play and inquiry (p. 97)." & "For example, children self-regulate when they \\
& are able to focus, sustain, and then switch \\
& their attention; sequence their thoughts; and \\
& ignore distractions (p. 55)."
\end{tabular}

sample quotations). Within the literature, co-regulation is described as the sharing of self-regulatory processes between a learner and a more proficient other person (or multiple people) during a short period of time (Hadwin \& Oshige, 2011). Both the literature and curriculum demonstrate the important role that co-regulation has in developing students' self-regulatory skills. The nature of 'sharing' these self-regulatory processes is emphasized in both the literature and the curriculum. For example, "They [the educators] use strategies such as modelling and conjecturing and engage in shared thinking with the children so that the children can learn to identify problems and propose innovative solutions" (ADEEWR, 2009, p. 15, as cited in OMOE, 2016, p. 90). In contrast to the empirical literature which suggests that co-regulation occurs between a learner and more proficient other person during a short period of time (Hadwin \& Oshige, 2011); the play-based curriculum discusses co-regulation more generally and define it as occurring in a single point of time rather than a process that can be ongoing.

\section{Theme 2: de-emphasis of behavior regulation toward a focus on emotional regulation}

Traditionally, the conceptualization of early self-regulation skills primarily focused on the need for children to manage and regulate their behaviors (Ponitz et al., 2009). Interestingly, the play-based kindergarten curriculum did not emphasize behavioral regulation in its operationalization of self-regulatory capacities (see Table 3 for an overview of Theme 2 with sample quotations). This was surprising given that our previous research with early years educators in kindergarten demonstrated that educators often consider self-control of behaviors to be the same as self-regulation (Timmons, 2018). In the literature, behavior regulation includes processes such as: stopping impulsive behaviors, paying attention, and following directions (Baumeister \& Vohs, 2004)). An instance where the conceptualization was consistent between the literature and the Kindergarten curriculum was managing behaviors in response to emotions as described here: "Through a variety of experiences in which they are supported in demonstrating their competence, children further develop the capacity to understand their own emotions and to express them with consideration and respect for others, to delay gratification, and to adapt their responses" (p. 48). Therefore, this quote within the policy document highlights the importance of emotional regulation but also the cognitive understanding of one's emotions as a broadened conceptualization. 
Table 4 Overview of Theme 3, example codes, and quotations

\begin{tabular}{|c|c|c|}
\hline Theme & Example codes & Example quotations \\
\hline \multirow[t]{2}{*}{$\begin{array}{l}\text { 3. Cognitive regulation encompasses far more than } \\
\text { inhibitory control }\end{array}$} & Focus & $\begin{array}{l}\text { "In connection with this frame, } \\
\text { it is important for educators to } \\
\text { consider: the role of the learning } \\
\text { environment in helping children } \\
\text { to be calm, focused, and alert } \\
\text { so they are better able to learn } \\
\text { (p. 54)." } \\
\text { "Behaviours such as humming or } \\
\text { chewing things, fidgeting (e.g., } \\
\text { tapping, jiggling), or constantly } \\
\text { moving may indicate that } \\
\text { the child is trying to remain } \\
\text { or become calm, alert, and } \\
\text { focused-in other words, that } \\
\text { the child is attempting to self- } \\
\text { regulate (p. 55)." }\end{array}$ \\
\hline & Attention & $\begin{array}{l}\text { "As part of making children's } \\
\text { transition to Kindergarten easier, } \\
\text { educators endeavour to maintain } \\
\text { a sense of calm in the classroom } \\
\text { and provide large blocks of time } \\
\text { to engage children's attention } \\
\text { in sustained, complex play and } \\
\text { inquiry (p. 97)." } \\
\text { "The educator observes that the } \\
\text { child is able to break off his atten- } \\
\text { tion but then return to reading } \\
\text { without losing the meaning of } \\
\text { the unfamiliar text (p. 156)." }\end{array}$ \\
\hline
\end{tabular}

An analysis of the FDK policy document suggests a shift to a more balanced conceptualization of self-regulation including other dimensions such as: metacognition, cognitive regulation, shared regulation, emotion regulation, and co-regulation. This is important as we move beyond the behavioral aspects of self-regulation to support educators in fostering children's abilities to monitor their emotions, cognition, and behavior to accomplish goals.

\section{Theme 3: cognitive regulation encompasses far more than inhibitory control}

Throughout the play-based kindergarten curriculum, cognitive regulation is commonly discussed in relation to the sub-constructs of attention and cognitive flexibility (see Table 4 for an overview of Theme 3 with sample quotations). Working memory and inhibitory control were mentioned infrequently. Again, this suggests that the Kindergarten program has shifted to a more holistic conceptualization of self-regulation rather than strictly focusing on managing behaviors. The curriculum used terminology such as cognitive flexibility, as an element of self-regulation, "Self-regulation involves attention skills, working memory, and cognitive flexibility-qualities that provide the underpinning for essential skills needed throughout life, such as planning and problem-solving skills" (Pascal, 2009a, p. 4, as cited in OMOE, 2016, p. 54).

In the literature, cognitive functions are conceptualized as being a component of behavioral regulation (McClelland et al., 2007). More specifically, behavioral regulation includes elements of executive functioning such as: inhibitory control, attention, and 
Table 5 Overview of Theme 4, example codes, and quotations

\begin{tabular}{|c|c|c|}
\hline Theme & Example codes & Example quotations \\
\hline \multirow[t]{3}{*}{$\begin{array}{l}\text { 4. A strong emphasis on the use of language } \\
\text { in supporting metacognition }\end{array}$} & Use language & $\begin{array}{l}\text { "Educators can support and encourage } \\
\text { Kindergarten children in innovative thinking } \\
\text { in such ways as the following: model the use } \\
\text { of language associated with problem solving } \\
\text { and innovating" (p. 90) }\end{array}$ \\
\hline & & $\begin{array}{l}\text { "Educators can support and encourage Kinder- } \\
\text { garten children in innovative thinking in such } \\
\text { ways as the following: encourage children to } \\
\text { use language and non-verbal means, such as } \\
\text { drawing diagrams, to explain their hypoth- } \\
\text { eses to others" (p. 90) }\end{array}$ \\
\hline & Aware & $\begin{array}{l}\text { "As they assimilate this understanding, children: } \\
\text { become aware that some words rhyme or } \\
\text { start or end in the same way, and thus begin } \\
\text { to develop phonological awareness" (p. } 67 \text { ) }\end{array}$ \\
\hline
\end{tabular}

working memory (Ponitz et al., 2009). In direct contrast to the literature, the play-based curriculum separated the multiple components of self-regulation (e.g., cognitive, biological and emotional, social, and prosocial) as described here, "For example, a child who attends to another child who has fallen and hurt himself demonstrates cognitive selfregulation (in recognizing the urgency of, and shifting attention to, an external event); biological and emotional self-regulation (in remaining calm enough to attend to the hurt child); and social self-regulation (in recognizing and understanding that a friend needs help and comfort), in addition to prosocial self-regulation (in acting on feelings of empathy and the desire to help a friend)" (pp. 55-56).

\section{Theme 4: a strong emphasis on the use of language in supporting metacognition}

The most frequent reference to metacognitive thinking in the play-based curriculum involves the use of language to articulate student thinking. The reference to awareness, planning skills, and reflection were less evident throughout the curriculum (see Table 5 for an overview of Theme 4 with sample quotations). Theoretically, the term metacognition encompasses much more than the capacity to use language to articulate your thinking. Multiple conceptualizations of metacognition exist in the literature, but metacognition can be understood as the knowledge that an individual has about their thinking and the control of their cognitive processes in relation to their thinking (Baker, 2010). Metacognition can be further broken down into three components: metacognitive knowledge, metacognitive regulation, and metacognitive experiences. Metacognitive knowledge are the general thoughts and beliefs that a learner has about their cognitive processes (Efklides, 2006; Flavell, 1979). For example, these may include thoughts about their strengths, weaknesses, and knowledge of strategies. Metacognitive regulation is the active process of monitoring and controlling one's learning (Flavell, 1979). For example, this includes setting goals, identifying resources, seeking clarification from the teacher. The third component, metacognitive experiences, includes the judgments and affective feelings that a learner have in relation to their learning (Ben-David \& Orion, 2013; Efklides, 2006). For example, a metacognitive experience could be when a student has a 'gut' feeling that something is not correct, and they change their answer. The metacognitive experiences have not been well-researched despite their 
practical applications of suggesting the need for a learner to change their process and strategy-use while learning (Efklides, 2006). All three components of metacognition are useful for learners and should be modeled by educators. The policy document suggested using language to talk about your thinking and learning as an important part of demonstrating metacognitive knowledge and regulation. However, it is well articulated throughout the literature that in order for students to develop their metacognition they need to have explicit instruction and opportunities for ongoing practice (Marulis et al., 2019; Sylva et al., 2010). Part of this modeling involves the use of language to articulate an individual's thinking. The curriculum elaborates further, "They share the language that enables children to identify and understand what they are doing" (p. 42). The use of questioning is also discussed as a way to encourage students to articulate their thinking which is the metacognitive process. At times this is discussed in relation to a specific curriculum area. For example, "The following are some examples of ways in which educators can engage the children: asking the children questions that elicit explanations of their mathematical thinking processes in various contexts" (p. 83). Despite the use of language being an important part of metacognition, teachers also need to understand the connection to goal-directed behaviors such as planning, monitoring, and evaluating as part of metacognition (metacognitive regulation). This theme suggests the need to move towards a more holistic conceptualization of metacognition aligned with the three components outlined in the literature above.

\section{Discussion and conclusion}

Despite consistent efforts to include self-regulation in early years curricula worldwide there is limited practical understanding of what self-regulation is and how best to support it in the day-to-day functions of a classroom. Ontario's innovative play-based kindergarten curriculum with a focus on self-regulation provided a unique opportunity to compare the practice-oriented conceptualization of self-regulation within the kindergarten curriculum with theory-driven models of self-regulation. In order to capture and evaluate these efforts in a critical way our team utilized a qualitative document analysis approach. Overall, the results demonstrate that the conceptualization and operationalization of self-regulation is evolving in both empirical literature and play-based kindergarten curricula. Specific findings from our research include the emergence of four overarching themes: (1) the power of co-regulation; (2) a de-emphasis of behavior regulation toward a focus on emotional regulation; (3) cognitive regulation encompasses far more than inhibitory control, and (4) the use of language in supporting metacognition. In analyzing the themes that emerged from this research, we acknowledge the efforts that the Ontario program has made to include empirically supported practices into the curriculum and recognize where more work is necessary. As such, we first highlight what the Ontario program is doing well to foster evidence-based self-regulation practices. Next, we provide explicit recommendations to ensure that emerging conceptualizations of self-regulation are promoted in early years curricula.

\section{Ontario's success}

Ontario's play-based kindergarten curriculum includes clear connections to empirical literature on self-regulation. The curriculum makes direct reference to Stuart Shanker's research (2013) on the five domains of self-regulation (biological, emotional, cognitive, social, and prosocial). In using Shanker's model of self-regulation, the curriculum 
moves beyond a limited operationalization focusing only on behavioral aspects such as self-control and compliance that are too often the focus of regulation in the early years, toward a more holistic conceptualization. For example, the self-regulation and wellbeing frame not only discuss the importance of students adapting to distractions, the curriculum also discusses children's learning and development of self-regulation skills with reference to regulating emotions, assessing consequences of actions in ways that allow students to engage more fully in learning opportunities, the interrelatedness of students self-awareness, sense of sense and the ability to self-regulate, and the role of the learning environment in supporting students attention (OMOE, 2016).

In discussing the learning environment and classroom climate the play-based curriculum discourages a regimented and overly controlled classroom. "A regimented classroom climate, in which all children are required to do the same thing at the same time in the same way, reduces feelings of control and discourages self-regulation" (Bronson, 2000, p. 234, as cited in OMOE, 2016, p. 57). It is important to note, however, that the curriculum does not discredit the importance of behavioral regulation and self-control, but instead takes a more holistic conceptualization that is fostered through a classroom context and positive relationships that serve to better support behavioral regulation of students. To illustrate this further, one of the curriculum expectations specifically focuses on self-control. For example, the curriculum states, "As children progress through the Kindergarten program, they... demonstrate self-control (e.g., be aware of and label their own emotions; accept help to calm down; calm themselves down after being upset) and adapt behavior to different contexts within the school environment (e.g., follow routines and rules in the classroom, gym, library, playground) (OMOE, 2016, p. 161). The curriculum provides explicit examples of what the children may say and do to demonstrate this expectation and examples of how the educators can intentionally respond to the child. For example, "The educators provide opportunities for the children to use language to express and regulate their emotions. The educators ask questions such as, "What do you notice happens to your body when you are angry or frustrated?"' (OMOE, 2016, pp. 161-162). Thus, findings from this research suggest a shift to a more balanced conceptualization of self-regulation. This is important as we move beyond the behavioral aspects of self-regulation to support educators in fostering children's abilities to monitor their emotions, cognition, and behavior to accomplish goals.

Two additional highlights of the Ontario program include acknowledgement of the role of play and the importance of socially shared co-regulation in the development of self-regulation skills in the early years. The need for students to be provided with multiple opportunities throughout the school day for co-regulation to occur was emphasized throughout the play-based curriculum. This process of co-regulation was described between students and educators, but also between students and their peers. Engaging techniques including the use of questioning are suggested as ways to support co-regulation through play interactions. Another example includes co-constructing the play environment as a strategy to purposefully engage students in their learning.

In discussing the role of play-based learning in the development of self-regulatory skills, the curriculum makes reference to the work of Vygotsky (1978) and connects socio-dramatic play ("pretend" play) and co-regulatory processes to children's developing self-regulation skills (OMOE, 2016). 
During socio-dramatic play, children naturally engage in learning that is in their "zone of proximal development"-in other words, learning that is at the "edge" of their capacities. Evidence may be seen in various play contexts in the classroom-children may be noticing for the first time that they can influence how water moves through a tube, that their shadow moves when they move, or how it feels to move a paintbrush over a canvas. As they notice and build on their insights, they are regulating their own learning. In socio-dramatic play, language becomes a self-regulatory tool. Children's private speech, or self-talk, is a mode through which they shift from external regulation (e.g., by a family member or educator) to self-regulation. Children begin to assimilate adult prompts, descriptions, explanations, and strategies by incorporating them into their self-talk. As they integrate the language they have heard into their own private speech, they are activating complex cognitive processes such as attention, memory, planning, and self-direction (Shanker, 2013b). Participants in socio-dramatic play communicate with each other using language and symbolic gestures to describe and extrapolate from familiar experiences, and to imagine and create new stories (OMOE, 2016, p. 20).

Overall, we acknowledge that the Ontario play-based kindergarten curriculum has made great efforts to include empirically supported self-regulation practices; however, given the expanding field of self-regulation we also want to provide explicit recommendations for policymakers and practitioners to ensure that emerging conceptualizations of self-regulation are promoted in early years curricula worldwide.

\section{Recommendations}

Despite many similarities between theory-driven conceptualizations and the play-based curriculum in Ontario, more work is needed to ensure that curriculum documents are promoting self-regulation skills and practices that are grounded in empirical findings. Moving forward, policymakers need to ensure that policy documents in the early years fully and accurately represent the abundance of literature surrounding the conceptualization of self-regulation. It is important that educators have explicit examples in policy documents (e.g., curriculum) demonstrating how they can encourage the development of all facets of self-regulation and not just those that have been the focus traditionally such as behavioral aspects of regulation. More specifically, educators may be more inclined to focus on the behavioral, social, and emotional facets of regulation as guided by their policies. Therefore, policies need to embed concrete examples of how to encourage cognitive regulation such as metacognitive thinking through think aloud and goalsetting. One mechanism that can be used to develop goal-directed learning is through the use of self-assessment. Young children in Kindergarten are capable of engaging in self-assessment, but it may look different to how it has been conceptualized in the literature with older students. Policy should consider ways to encourage educators to share how they use self-assessment in their Kindergarten programs to promote self-assessment as more of a widespread practice across Kindergarten classrooms.

Additionally, greater emphasis should be placed on the shift towards co-regulation especially given the context of early years where young students may be incapable of regulating their behaviors, emotions, and cognitive processes independently when they first start formal schooling. As such, it is imperative that co-regulation becomes a hallmark of Kindergarten programming. Given the important role that co-regulation can play in 
the early years, policymakers need to provide explicit (and theory based) definitions of co-regulation and social shared regulation. Further, these definitions need to be accompanied by direct examples of how educators can facilitate co-regulation between themselves and students but also between students.

Lastly, given that self-regulation is a part of many Kindergarten policy documents and curricula, it is important that teachers have examples of how they can assess self-regulation in the early years. Therefore, educators need tools to aid them with assessing self-regulation in real-time while observing students. These tools should aim to collect quantitative (e.g., frequency) and qualitative (narrative) data surrounding each component of self-regulation. Providing educators with these tools may also help them to promote more well-rounded self-regulation behaviors (e.g., cognitive). This study provides insight into how early years policy documents could be further aligned with empirical literature on self-regulation.

Acknowledgements

Not applicable.

Authors' contributions

$\mathrm{HB}$ and KT developed the analysis plan and co-constructed the codebook. HB was the lead coder for the analysis while $\mathrm{KT}$ was a second coder and helped with interpretation of the data. HB and KT co-wrote the manuscript.

\section{Authors' information}

$\mathrm{HB}$ completed her PhD at Queen's Faculty of Education as a member of the Assessment and Evaluation Group and the Early Childhood Education lab. She is a mixed methodologist with expertise in formative assessment and understanding cognitive processes across the learning continuum. Her doctoral research explored the relationship between assessment and self-regulation in Ontario Kindergarten classrooms.

KT is an assistant professor in Early Childhood Education at Queen's Faculty of Education and the head of the Early Childhood Education lab and associated with the Assessment and Evaluation Group. She is also a mixed methodologist who explores early childhood development, kindergarten, play-based learning, educator expectations, and self-regulation.

\section{Funding}

The data analysis and development of the manuscript was supported by a Queen's University, Faculty of Education, 2018 seed Grant.

\section{Availability of data and materials}

The datasets used and/or analyzed during the current study are available from the corresponding author on reasonable request.

\section{Declarations}

\section{Competing interests}

The authors declare that they have no competing interests.

Received: 12 December 2019 Accepted: 21 July 2021

Published online: 03 August 2021

\section{References}

Bailey, A. L., \& Heritage, M. (2018). Self-regulation in learning: The role of language and formative assessment. Harvard Education Press.

Baker, L. (2010). Metacognition. Learning and cognition-issues and concepts (pp. 204-210). Elsevier.

Bandura, A. (1982). Self-efficacy mechanism in human agency. American Psychologist, 37(2), 122-147. https://doi.org/10. 1037/0003-066X.37.2.122.

Bandura, A. (1986). Social foundation of thought and action: A social cognitive theory. Prentice-Hall.

Bauer, I., \& Baumeister, R. (2011). Self-regulatory strength. In K. Vohs \& R. Baumeister (Eds.), Handbook of self-regulation (2nd ed., pp. 64-82). The Guilford Press.

Baumeister, R. F., \&Vohs, K. D. (2004). Handbook of self-regulation: Research, theory, and applications. Guilford Press.

Baumeister, R. F., \& Vohs, K. D. (2011). Handbook of self-regulation: Research, theory, and applications (2nd ed.). Guilford Press.

Bautista, A., Habib, M., Eng, A., \& Bull, R. (2019). Purposeful play during learning centre time: From curriculum to practice. Journal of Curriculum Studies, 51(5), 715-736. https://doi.org/10.1080/00220272.2019.1611928. 
Becker, D. R., McClelland, M. M., Loprinzi, P., \& Trost, S. G. (2014). Physical activity, self-regulation, and early academic achievement in preschool children. Early Education \& Development, 25, 56-70. https://doi.org/10.1080/10409289. 2013.780505 .

Ben-David, A., \& Orion, N. (2013). Teachers' voices on integrating metacognition into science education. International Journal of Science Education, 35(18), 3161-3193. https://doi.org/10.1080/09500693.2012.697208.

Bergen, D. (2009). Play as the learning medium for future scientists, mathematicians, and engineers. American Journal of Play., 1(4), 413-428.

Best, J. R., \& Miller, P. H. (2010). A developmental perspective on executive function. Child Development, 81, 1641-1660. https://doi.org/10.1111/j.1467-8624.2010.01499.x

Blair, C., \& Diamond, A. (2008). Biological processes in prevention and intervention: The promotion of self-regulation as a means of preventing school failure. Development and Psychopathology, 20, 899-911. https://doi.org/10.1017/S0954 579408000436.

Blair, C., \& Raver, C. (2015). School readiness and self-regulation: A developmental psychobiological approach. Annual Review Psychology, 66, 711-731. https://doi.org/10.1146/annurev-psych-010814-015221.

Blair, C., \& Razza, R. P. (2007). Relating effortful control, executive function, and false belief understanding to emerging math and literacy ability in kindergarten. Child Development, 78(2), 647-663. https://doi.org/10.1111/j.1467-8624 2007.01019.x.

Bodrova, E., \& Leong, D. (2008). Developing self-regulation in kindergarten: Can we keep all the crickets in the basket? Young Children, 63(2), 56-58.

Boekaerts, M., \& Corno, L. (2005). Self-regulation in the classroom: A perspective on assessment and intervention. Applied Psychology and International Review, 54(2), 199-231. https://doi.org/10.1111/j.1464-0597.2005.00205.x.

Bowen, G. A. (2009). Document analysis as a qualitative research method. Qualitative Research Journal, 9(2), 27-40. https:// doi.org/10.3316/QRJ0902027.

Bronson, M.B. (2000). Self-regulation in early childhood: Nature and nurture. New York: Guilford Press.

Burman, J.T., Green, C. D., \& Shanker, S. (2015). On the meanings of self-regulation: Digital humanities in service of conceptual clarity. Child Development, 86(5), 1507-1521. https://doi.org/10.1111/cdev.12395.

Chen, P. P., \& Bonner, S. M. (2019). A framework for classroom assessment, learning, and self-regulation. Assessment in Education: Principles, Policy \& Practice. https://doi.org/10.1080/0969594x.2019.1619515.

Clark, I. (2012). Formative assessment: Assessment is for self-regulated learning. Educational Psychology Review, 24(2), 205-249. https://doi.org/10.1007/s10648-011-9191-6.

Cleary, T. J., \& Chen, P. P. (2009). Self-regulation, motivation, and math achievement in middle school: Variations across grade level and math context. Journal of School Psychology, 47(5), 291-314. https://doi.org/10.1016/j.jsp.2009.04. 002.

Diamond, A., \& Lee, K. (2011). Interventions shown to aid executive function development in children 4 to 12 years old. Science, 333, 959-964. https://doi.org/10.1126/science.1204529.

Duckworth, A. L., Grant, H., Loew, B., Oettingen, G., \& Gollwitzer, P. (2011). Self-regulation strategies improve selfdiscipline in adolescents: Benefits of mental contrasting and implementation intentions. Educational Psychology, 31(1), 17-26. https://doi.org/10.1080/01443410.2010.506003.

Durlak, J. A., Weissberg, R. P., Dymnicki, A. B., Taylor, R. D., \& Schelinger, K. B. (2011). The impact of enhancing students' social and emotional learning: A meta-analysis of school-based universal interventions. Child Development, 82(1), 405-432. https://doi.org/10.1111/j.1467-8624.2010.01564.x.

Edossa, A. K., Schroeders, U., Weinert, S., \& Artelt, C. (2017). The development of emotional and behavioral self-regulation and their effects on academic achievement in childhood. International Journal of Behavioral Development, 42(2), 192-202. https://doi.org/10.1177/0165025416687412.

Efklides, A. (2006). Metacognition and affect: What can metacognitive experiences tell us about the learning process? Educational Research Review, 1(1), 3-14. https://doi.org/10.1016/j.edurev.2005.11.001.

Flavell, J. H. (1979). Metacognition and cognitive monitoring. American Psychologist, 34, 906-911. https://doi.org/10. 1037/0003-066X.34.10.906.

Gullo, D. F., \& Hughes, K. (2011). Reclaiming kindergarten: Part I. Questions about theory and practice. Early Childhood Education Journal, 38, 323-328. https://doi.org/10.1007/s10643-010-0429-6.

Hadwin, A. F., Järvelä, S., \& Miller, M. (2011). Self-regulated, co-regulated and socially shared regulation of learning In B. J. Zimmerman \& D. H. Schunk (Eds.), Handbook of self-regulation of learning and performance (pp. 65-84). Routledge.

Hadwin, A., \& Oshige, M. (2011). Self-regulation, coregulation, and socially shared regulation: Exploring perspectives of social in self-regulated learning theory. Teachers College Record, 113(2), 240-264.

Hadwin, A. F., Oshige, M., Gress, C. L., \& Winne, P. H. (2010). Innovative ways for using gStudy to orchestrate and research social aspects of self-regulated learning. Computers in Human Behaviour, 26(5), 794-805. https://doi. org/10.1016/j.chb.2007.06.007.

Hawes, Z., Gibson, A., Mir, S., \& Pelletier, J. (2012). Children's experiences in full-day programs for 4- and 5-year-olds: Play and self-regulation. In Toronto first duty: Phase 3 report. Atkinson Centre for Society and Child Development, OISE, University of Toronto. http://www1.toronto.ca/City\%200f\%20Toronto/Children\%27s\%20Services/ Divisional\%20Profile/Past\%20Projects/firstduty/tfd_phase3report.pdf.

Howse, R. B., Calkins, S. D., Anastopoulos, A. D., Keane, S. P., \& Shelton, T. L. (2003). Regulatory contributors to children's kindergarten achievement. Early Education and Development, 14, 101-120. https://doi.org/10.1207/s15566935e ed1401_7.

Jackson, T., Mackenzie, J., \& Hobfoll, S. E. (2000). Communal aspects of self-regulation. In M. Boekaerts, P. R. Pintrich, \& M. Zeidner (Eds.), Handbook of self-regulation (pp. 275-300). Academic Press. https://doi.org/10.1016/B978-01210 9890-2/50038-X.

Kurki, K., Järvenoja, H., Järvelä, S., \& Mykkänen, A. (2016). How teachers co-regulate children's emotions and behaviour in socio-emotionally challenging situations in day-care settings. International Journal of Educational Research, 76(Complete), 76-88. https://doi.org/10.1016/j.ijer.2016.02.002. 
Lonigan, C. J., Allan, D. M., \& Phillips, B. M. (2017). Examining the predictive relations between two aspects of selfregulation and growth in preschool children's early literacy skills. Developmental Psychology, 53, 63-76. https:// doi.org/10.1037/dev0000247.

Lynch, M. (2014). Ontario kindergarten teachers' social media discussion about full day kindergarten. McGill Journal of Education, 49(2), 329-347. https://doi.org/10.7202/1029423ar.

Marulis, L. M., Baker, S. T., \& Whitebread, D. (2019). Integrating metacognition and executive function to enhance young children's perception of and agency in their learning. Early Childhood Research Quarterly. https://doi.org/ 10.1016/j.ecresq.2018.12.017.

McCain, M., Mustard, F., \& McCuaig, K. (2011). Early years study 3: Making decisions, taking action. Paper presented at the Margaret and Wallace McCain Family Foundation, Toronto, ON.

McCaslin, M. (2009). Co-regulation of student motivation and emergent identity. Educational Psychologist, 44 137-146. https://doi.org/10.1080/00461520902832384.

McCaslin, M., \& Hickey, D. T. (2001). Self-regulated learning and academic achievement: A Vygotskian view. In B. J. Zimmerman \& D. H. Schunk (Eds.), Self-regulated learning and academic achievement (pp. 227-252). Lawrence Erlbaum Associates.

McClelland, M. M., \& Cameron, C. E. (2012). Self-regulation in early childhood: improving conceptual clarity and developing ecologically valid measures. Child Development Perspectives, 6(2), 136-142. https://doi.org/10.1111/j. 1750-8606.2011.00191.x.

McClelland, M. M., Cameron, C. E., Wanless, S., \& Murray, A. (2007). Executive function, behavioral self-regulation, and social-emotional competence: Links to school readiness. In O. N. Saracho \& B. Spodek (Eds.), Contemporary perspectives in early childhood education: Social learning in early childhood education (Vol. 7, pp. 113-137). Information Age.

Meusen-Beekman, K. D., Joosten-ten Brinke, D. E., \& Boshuizen, H. P. A. (2015). Developing young adolescents'selfregulation by means of formative assessment: A theoretical perspective. Cogent Education. https://doi.org/10. 1080/2331186x.2015.1071233.

Moffitt, T. E., Arseneault, L., Belsky, J., Dickson, N., Hancox, R. J., Harrington, H., et al. (2011). A gradient of childhood self-control predicts health, wealth, and public safety. Proceedings of the National Academy of Sciences, 108, 2693-2698. https://doi.org/10.1073/pnas.1010076108.

Neumann, E. (1971). The elements of play. MSS Information Corp.

Nicolopoulou, A. (2010). The alarming disappearance of play from early childhood education. Human Development, 53(1), 1-4. https://doi.org/10.1159/000268135.

Ontario Ministry of Education (OMOE). (2016). The Kindergarten Program. Retrieved from https://www.ontario.ca/ document/kindergarten-program-2016?_ga=2.89272216.204380264.1570804212-1211174662.1570804212.

Ontario Ministry of Education (OMOE) (2021b). Education facts, 2019-2020* (Preliminary). Retrieved from http:// www.edu.gov.on.ca/eng/educationfacts.html.

Ontario Ministry of Education (OMOE) (2021a). Full-Day Kindergarten. Retrieved from http://www.edu.gov.on.ca/kinde rgarten/index.html.

Panadero, E., Andrade, H., \& Brookhart, S. (2018). Fusing self-regulated learning and formative assessment: A roadmap of where we are, how we got here, and where we are going. The Australian Educational Researcher, 45(1), 13-31. https://doi.org/10.1007/s13384-018-0258-y.

Pandey, A., Hale, D., Das, S., Goddings, A. L., Blakemore, S. J., \& Viner, R. M. (2018). Effectiveness of universal self-regulation-based interventions in children and adolescents. JAMA Pediatrics. https://doi.org/10.1001/jamapediatrics. 2018.0232.

Pascal, C. (2009a). Every child, every opportunity: Curriculum and pedagogy for the early learning program. (A compendium report to C. Pascal, [2009], With our best future in mind: Implementing early learning in Ontario). Toronto: Queen's Printer for Ontario.

Perels, F., Merget-Kullmann, M., Wende, M., Schmitz, B., \& Buchbinder, C. (2009). Improving self-regulated learning of preschool children: Evaluation of training for kindergarten teachers. British Journal of Educational Psychology, 79(Pt 2), 311-327. https://doi.org/10.1348/000709908X322875.

Ponitz, C. C., McClelland, M. M., Matthews, J. S., \& Morrison, F. J. (2009). A structured observation of behavioral selfregulation and its contribution to kindergarten outcomes. Developmental Psychology, 45(3), 605-619. https://doi. org/10.1037/a0015365.

Pyle, A., \& Danniels, E. (2017). A continuum of play-based learning: The role of the teacher in play-based pedagogy and the fear of hijacking play. Early Education and Development, 28(3), 274-289. https://doi.org/10.1080/10409 289.2016.1220771.

Pyle, A., \& DeLuca, C. (2017). Assessment in play-based kindergarten classrooms: An empirical study of teacher perspectives and practices. The Journal of Educational Research, 110(5), 457-466. https://doi.org/10.1080/00220 671.2015.1118005.

Rothbart, M. K., Posner, M. I., \& Kieras, J. (2006). Temperament, attention, and the development of self-regulation. In K. McCartney \& D. Phillips (Eds.), Blackwell handbook of early childhood development (pp. 338-357). Blackwell. https://doi.org/10.1002/9780470757703.ch17.

Scholer, A. A., Miele, D. B., Murayama, K., \& Fujita, K. (2018). New directions in self-regulation: The role of metamotivational beliefs. Current Directions in Psychological Science, 27(6), 437-442. https://doi.org/10.1177/0963721418 790549.

Schunk, D. H., \& Zimmerman, B. J. (Eds.). (1994). Self-regulation of learning and performance: Issues and educational applications. Erlbaum.

Shanker, S. (2017). What you need to know. Self-regulation: The early years. The MEHRIT Centre. Retrieved from https:// self-reg.ca/self-reg/self-regknowledge-series/.

Shanker, S. (2017). What you need to know. Self-Regulation: 5 domains of self-reg. The MEHRIT Centre. Retrieved from https://self-reg.ca/self-reg/self-regknowledge-series/. 
Smith, K., Gamlem, S., Sandal, A., \& Engelsen, K. (2016). Educating for the future: A conceptual framework of responsive pedagogy. Cogent Education, 3, 1-12. https://doi.org/10.1080/2331186X.2016.1227021.

Sylva, K., Melhuish, E., Sammons, P., Siraj-Blatchford, I., \& Taggart, B. (2010). Early childhood matters. Routledge.

Timmons, K. (2018). Educator expectations in full-day kindergarten: Comparing the factors that contribute to the formation of early childhood educator and teacher expectations. Early Childhood Education Journal, 46(6), 613-628. https://doi.org/10.1007/s10643-018-0891-0.

Timmons, K. (2019). Kindergarten expectations and outcomes: Understanding the influence of educator and child expectations on children's self-regulation, early reading and vocabulary outcomes. Journal of Research in Childhood Education, 33(3), 471-489. https://doi.org/10.1080/02568543.2019.1609144.

Timmons, K., Pelletier, J., \& Corter, C. (2016). Understanding children's self-regulation within different classroom contexts. Early Child Development and Care, 186(2), 249-267. https://doi.org/10.1080/03004430.2015.1027699.

Vohs, K., \& Baumeister, R. F. (Eds.). (2017). Handbook of self-regulation: Research, applications (3rd ed.). Guilford.

Vygotsky, L. (1978). Mind in society: The development of higher psychological processes (rev. ed.). Boston: Harvard University Press.

Whitebread, D., Bingham, S., Grau, V., Pasternak, D. P., \& Sangster, C. (2007). Development of metacognition and self-regulated learning in young children: Role of collaborative and peer-assisted learning. Journal of Cognitive Education and Psychology, 6(3), 433-455. https://doi.org/10.1891/194589507787382043.

Whitebread, D., Coltman, P., Pasternak, D. P., Sangster, C., Grau, V., Bingham, S., et al. (2009). The development of two observational tools for assessing metacognition and self-regulated learning in young children. Metacognition and Learning, 4(1), 63-85. https://doi.org/10.1007/s11409-008-9033-1.

Youmans, A., Kirby, J., \& Freeman, J. (2018). How effectively does the full-day, play-based kindergarten programme in Ontario promote self-regulation, literacy, and numeracy? Early Child Development and Care, 188(12), 1788-1800. https://doi.org/10.1080/03004430.2017.1287177.

Zimmerman, B. J. (2000). Attaining self-regulation: A social cognitive perspective. In M. Boekaerts, P. R. Pintrich, \& M. Zeidner (Eds.), Handbook of self-regulation. Academic Press.

Zimmerman, B. J. (2002). Becoming a self-regulated learner: An overview. Theory into Practice, 41(2), 64-70. https:// doi.org/10.1207/s15430421tip4102_2.

Zimmerman, B. J., \& Schunk, D. H. (Eds.). (2001). Self-regulated learning and academic achievement: Theoretical perspectives (2nd ed.). Erlbaum.

\section{Publisher's Note}

Springer Nature remains neutral with regard to jurisdictional claims in published maps and institutional affiliations.

\section{Submit your manuscript to a SpringerOpen ${ }^{\circ}$ journal and benefit from:}

- Convenient online submission

- Rigorous peer review

- Open access: articles freely available online

- High visibility within the field

Retaining the copyright to your article

Submit your next manuscript at $\boldsymbol{s p r i n g e r o p e n . c o m ~}$ 